\title{
O uso das Plataformas Digitais pelas IES no contexto de afastamento social pela Covid-19
}

\section{Camila Bahia Góes}

Doutoranda do Programa de PósGraduação em Educação (PPGE) da Universidade Federal da Bahia (UFBA). Membro do Laboratório de Tecnologias Informacionais e Inclusão Sociodigital (LTI Digital)

camilabagoes@gmail.com

\section{Glauber Cassiano}

Mestrando do Programa de PósGraduação em Educação (PPGE) da Universidade Federal da Bahia (UFBA). Membro do Laboratório de Tecnologias Informacionais e Inclusão Sociodigital (LTI Digital).

glauber.cassiano@ufba.br

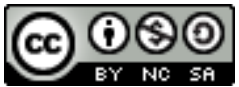

Este trabalho está licenciado com uma Licença Creative Commons - AtribuiçãoNãoComercial-Compartilhalgual 4.0

Internacional.

\section{Resumo}

Este estudo teve como objetivo analisar a percepção dos professores das IES sobre o uso das plataformas digitais durante o afastamento social causado pela Covid-19. O afastamento social direcionou para novas formas de se relacionar na sociedade e as Instituições de Ensino Superior (IES), principalmente, as de rede privada, precisaram se adaptar a nova ordem social a fim de que não prejudicasse o semestre acadêmico, adotando então, o ensino remoto como prática institucional através do uso das plataformas digitais para o processo de ensino e aprendizagem. Foi realizada uma pesquisa exploratória com 10 professores de IES distintas, selecionados por atuarem especificamente no curso de Pedagogia, e através do questionário construído no Formulário Google foi feito o levantamento das narrativas dos mesmos. Como resultado, percebe-se que os desafios entornam diante dos pontos de boa conectividade; ausência de recursos adequados; acesso á Internet; ausência dos estudantes nas aulas remotas, formação adequada dos professores para o domínio das ferramentas e outros.

Palavras-chave: Plataformas digitais. Ensino remoto. Instituições de Ensino Superior. Afastamento Social.

\section{The use of digital platforms by higher education institutions in the context of social removal by Covid-19}

\begin{abstract}
This study aimed to analyze the perception of teachers at Higher Education Institutions about the use of digital platforms during the social withdrawal caused by Covid-19. Social exclusion led to new ways of relating in society and Higher Education Institutions, especially those in the private network, needed to adapt to the new social order so that it would not harm the academic semester, they then adopted remote education as institutional practice through the use of digital platforms for the teaching and learning process. We conducted an exploratory research with 10 teachers from different Higher Education Institutions, selected for working specifically in the Pedagogy course, and through the questionnaire built on the Google Form, their narratives were surveyed. It is noticed that the challenges spill over before the points of good connectivity; lack of adequate resources; Internet access; absence of students in remote classes, adequate training of teachers to master tools and others.
\end{abstract}

Keywords: Digital platforms. Remote teaching. Higher Education Institutions. Social Withdrawal. 


\section{Introdução}

$\mathrm{Na}$ segunda metade de 2019, a China foi acometida por um vírus conhecido como coronavírus SARS-COV-2, que em se espalhou rapidamente pelo mundo no primeiro semestre em 2020. Trata-se de uma família de vírus que causa infecções respiratórias, provocando a doença chamada de Covid-19 com sintomas de: tosse; febre; coriza; dor de garganta e dificuldade para respirar, o que pode levar o sujeito a óbito, a depender do sistema imunológico de cada pessoa.

Por conta de ser um vírus que se transmite pelo contato através do aperto de mão; gotículas de saliva; espirro; tosse; catarro; e, objetos ou superfícies contaminadas, como celulares, mesas, maçanetas, brinquedos, teclados de computador etc. foi necessário uma reorganização social no que diz respeito à forma das pessoas se relacionarem e desenvolverem suas atividades coletivas. Proposto, a partir disso, um afastamento social que prive as pessoas de aglomerações ou contatos desnecessários, ou seja, escolas, faculdades, comércio, restaurantes, bancos, dentre outros, espaços de coletividade foram fechados e estruturados para atender as demandas mais emergenciais. Conforme a Nota Técnica' 'Ensino a distância Educação Básica frente à pandemia da Covid-19' emitida pela organização Todos Pela Educação² (2020, não paginado), "[...] a pandemia da Covid-19 vem trazendo imensos desafios para todos os setores, no Brasil e no mundo. Na tentativa de reduzir a ampla disseminação do novo Coronavírus, medidas de distanciamento social têm sido adotadas pelos países, e ainda não se sabe exatamente quando deixarão de ser necessárias".

Neste contexto de afastamento social, o qual direciona para novas formas de se relacionar, houve necessidade das Instituições de Ensino Superior (IES), principalmente, as de rede privada, de se adaptar a nova ordem social a fim de que não prejudique o semestre acadêmico. Por isso, orientou-se e institucionalizou-se práticas realizadas através das plataformas digitais, como uma tecnologia já estabelecida e necessária à apropriação por parte de todos os humanos para assegurar o viver em sociedade (NEVES, 2010) e indispensáveis para o processo de ensino e aprendizagem.

Sabe-se que as plataformas digitais, sem desconsiderar suas potencialidades, apresentam limitações no que diz respeito a: acesso; aparatos tecnológicos necessários; quantidade de pessoas por acesso; qualidade de internet, dentre outras. Dessa forma, surge o seguinte questionamento: Como os professores das IES analisam o uso das plataformas digitais no contexto de afastamento social pela Covid-19? A fim de responder tal problemática, o estudo teve como objetivo de analisar a percepção dos professores das IES sobre o uso das plataformas digitais durante o afastamento social causado pela Covid19.

Este estudo apresenta uma proposta crítica diante do uso das tecnologias nas propostas educacionais, sobretudo, diante da adesão das plataformas digitais como ferramentas para a interação do professor e estudante diante do contexto de pandemia nas IES. Entretanto, sem a pretensão de descaracterizar o potencial da tecnologia e do que os artefatos tecnológicos oferecem para manter as relações no processo de ensino e aprendizagem, porém, apresentando pontos que devem ser discutidos e refletidos enquanto complicadores para o direcionamento dos mesmos na prática educacional.

\section{Procedimentos Metodológicos}

Para a realização deste estudo, tivemos a abordagem qualitativa como égide metodológica realizada através de revisão de literatura e pesquisa exploratória. Como descritores de busca literária, combinamos os termos da pesquisa: plataformas digitais, afastamento social e ensino remoto. As bases de dados utilizadas para seleção dos textos da revisão de literatura foram a Education Full Text, Eric (CSA), Periódicos CAPES e SciELO. Para a pesquisa exploratória foi utilizada a técnica de entrevista, contamos com a colaboração de 10 professores de Instituições de Ensino Superior distintas, localizadas nas cidades de Feira de Santana-BA e Cachoeira-BA, atuantes especificamente no curso de Pedagogia, por entender que este público apresenta questões sociais e econômicas que podem vir a dificultar o acesso e acompanhamento das aulas propostas nas plataformas digitais. Para tanto, foi utilizado o instrumento de questionário, construído através da ferramenta Google Formulários, lançado via WhatsApp e E-mail para o preenchimento dos professores. Vale ressaltar que os professores atuam

\footnotetext{
${ }^{1}$ Primeira versão de um documento em construção e para debate sobre o Ensino a distância na Educação Básica frente à pandemia da Covid-19, considerando que as discussões sobre o tema estão em constante amadurecimento neste momento.

${ }^{2}$ Organização da sociedade civil, sem fins lucrativos, plural e suprapartidária, fundada em 2006. Com uma atuação independente e sem receber recursos públicos, nosso foco é contribuir para melhorar a Educação Básica no Brasil.
} 
entre os $1^{\circ}$ a $8^{\circ}$ semestres do curso de Pedagogia, prevalecendo em maior quantidade, nos semestres de atuação: $1^{\circ}$, $3^{\circ}, 5^{\circ}$ e 6 .

Sabe-se que em relação às plataformas digitais, existe uma variedade de possibilidades adotadas pelas instituições ou pelos professores individualmente, e no caso dos professores colaboradores, foi levantado que o Google Meet ${ }^{3}$ é a plataforma mais utilizada, com porcentagem apresentada de 71,4\%, em seguida de, Zoom e Skype, com 14,3\% para cada uma delas. O que nos revela a institucionalização da plataforma Google Meet para o desenvolvimento do ensino remoto.

Para melhor compreensão do que se propõe a discutir neste estudo, organizamos o artigo em duas sessões, apresentadas a partir de uma discussão teórica inicial sobre as implicações e proposições que entornam as plataformas digitais nas IES e, em seguida, a análise das narrativas apresentadas pelos professores das Instituições diante do uso das plataformas digitais neste contexto, à luz da base teórica de Marcuse (2001); Feenberg (2001; 2002); Maschio (2015); Masetto (2003); Neves (2010); Neves, Santos e Gomes (2012); dentre outros.

\section{As plataformas digitais nas IES: implicações e proposições}

Para melhor compreensão deste tópico, gostaríamos de inicialmente estabelecer alguns fundamentos teóricos que nos guiarão no desenvolvimento das ideias aqui discutidas. O primeiro deles é de que a luz do pensamento de Marcuse (2001), as novas tecnologias podem ser utilizadas como um instrumento de dominação e controle, ou seja, possui potencial para organizar e perpetuar as relações sociais, manifestação do pensamento prevalecente e dos modelos de comportamento.

Partindo da concepção teórica de Feenberg (2001; 2002), entendemos que por ser um artefato cultural, a tecnologia não está livre de influências históricas, políticas e culturais. Portanto, a concepção teórica de tecnologia que irá conduzir-nos a partir de então, sugere que a tecnologia é carregada de valores, isso nos leva a acreditar que os meios implicam necessariamente em fins; no tocante a sua autonomia, cremos que os meios e fins são determinados pelo sistema, ou seja, impera a vertente, onde preconiza-se que a tecnologia possui valores intrínsecos e não pode ser utilizada para propósitos diferentes desses; por fim, à luz da teoria crítica da tecnologia entendemos que a tecnologia pode ser controlada e que é carregada de valores. Nessa perspectiva, "[...] a tecnologia não é vista como um instrumento, como um objeto neutro, mas como uma estrutura para um estilo de vida" (OLIVEIRA; GUIMARÃES; LORENZETTI, 2016, p. 128).

Nos últimos dias, foi possível observar que mais do que nunca as tecnologias digitais ${ }^{4}$ tiveram uma presença constante na organização das práticas sociais, tornando-se para o atual contexto uma das principais características da sociedade contemporânea. O afastamento social provocado pelo Covid-19, impôs as IES privadas no Brasil a necessidade de articularse rapidamente em busca de uma proposta de ensino remoto visando o término do semestre letivo de 2020.1 de tal maneira que minorasse as percas em decorrência da pandemia. Desta forma, as plataformas digitais de ensino remoto, tais como Google Meet, Zoom, Skype, Google Classroom, dentre outras, ocuparam um papel de protagonismo nesse processo.

Esta nova realidade desafiou e certamente continuará desafiando as práticas docentes de ensino e aprendizagem de agora em diante. Resta-nos descobrir e refletir quais são as implicações e proposições, os limites e as possibilidades destes instrumentos tecnológicos digitais no âmbito acadêmico superior. Uma coisa parece certa, o ensino híbrido e a educação plenamente à distância ganham a partir de então, uma nova perspectiva e atenção não só da classe política, mas empresarial também, no Brasil e no resto do mundo.

\footnotetext{
${ }^{3}$ É uma ferramenta incorporada ao portfólio de soluções do G Suite, para a realização de reuniões virtuais, no qual as pessoas podem participar de onde estiverem, remotamente. Disponível em: https://ppgcs.ufv.br/wp-content/uploads/2020/05/Tutorial-do-Google-Meet.pdf. Acesso em: 23 jun. 2020.

${ }^{4}$ Tecnologia digital é um conjunto de tecnologias que permite, principalmente, a transformação de qualquer linguagem ou dado em números, isto é, em zeros e uns $(0$ e 1$)$. As tecnologias digitais possibilitam vantagens logísticas e pedagógicas inesperadas, como por exemplo: a transmissão rápida de informações a qualquer momento e para toda parte, genuínas possibilidades para a aprendizagem autônoma, maior interatividade, mais orientação para os/as estudantes, maior individualização, melhor qualidade dos programas e maior eficácia da aprendizagem (SOUSA; MOITA; CARVALHO, 2011).
} 
A necessidade está posta, o uso das tecnologias digitais como, por exemplo, as plataformas digitais no contexto educacional passarão a ganhar maior destaque, no entanto, é importante estar atento aos movimentos geradores de pseudonecessidades de uso desequilibrado destas tecnologias digitais frente ao processo educacional nas IES no âmbito público e privado. Ou seja, ainda que neste primeiro momento, tenha ficado claro o grande benefício do uso destas plataformas, dos artefatos e ferramentas digitais para conclusão do semestre letivo, isso não quer dizer que devamos partir de um extremo para o outro, isso seria um ato agressivo em si contra a educação do nosso país, uma barbárie.

A necessidade de civilização digital no contexto da educação é iminente, e é evidente que há potencialidades nas plataformas digitais quando se pensa em alcançar este objetivo. As IES terão um papel fundamental nesse processo, ao inserir de forma moderada e contextualizada tais instrumentos tecnológicos. No entanto, conforme destacou Pucci (2012, p. 12), "[...] há uma ambiguidade na tecnologia, que não se resume apenas no uso que se faz dela: se é utilizada para o bem ela é eticamente correta; se é utilizada para o mal é falsa", entendamos o mal aqui citado como interesses escusos de ordem econômica por exemplo.

As IES, os alunos e os docentes precisam compreender que há uma intencionalidade de precisão e funcionalidade nos aparatos tecnológicos que, mesmo quando utilizados para minorar a dor dos homens, geram frieza, distância e manipulação. É preciso equilibrar sua oferta, avaliá-la e aperfeiçoá-la sem que haja extremismos.

A tendência natural a partir de agora é de considerar as plataformas digitais como algo em si, 'salvadoras da pátria', elemento único e exclusivo do sucesso em termos de enfrentamento da crise social tal qual as IES e toda a sociedade mundial acabaram de enfrentar com a Covid-19; fazendo-nos esquecer de que esta é, porém, um braço prolongado do homem.

De fato, há potencial nas tecnologias educacionais digitais, já podemos afirmar que estas ocupam uma posição chave no processo de ensino e aprendizagem do presente e do futuro. Elas ajudarão o ensino híbrido a produzir 'pessoas tecnológicas', afinadas com as novas tecnologias, as novas demandas sociais, o novo mundo, por outro lado, conforme Adorno (2000 apud PUCCI, 2012, p. 13) "[...] a racionalização dos procedimentos técnicos é mais benéfica à produtividade do trabalho do que aos próprios trabalhadores". Assim sendo, poderíamos correr o risco de tornar-nos uma sociedade puramente digital.

Mas enfim, se a sociedade se modifica, a escola e as IES tendem a acompanhar, ainda que de forma lenta, há transformações. Para Maschio (2015, p. 579), "[...] vivemos imersos na cultura digital. Cada vez mais nossa sociedade apresenta múltiplas formas de comunicação e interação proporcionadas pelos meios virtuais. A materialidade se modifica, as tecnologias avançam em uma velocidade vertiginosa". A cultura educacional hibrida põe em evidência saberes, dispositivos, plataformas digitais, artefatos tecnológicos, normativas, discursos pedagógicos, enfim, práticas de ensino que compõe o próprio processo de ensino e aprendizagem.

Considerar a inserção e a apropriação das tecnologias digitais (plataformas, ferramentas e outros artefatos tecnológicos) na IES na sua dimensão prática, é observar como essas implicam na alteração dos comportamentos, na configuração dos discursos sobre o ensino e a aprendizagem, e na produção de um fazer institucional (MASCHIO, 2015). Uma vez que as tecnologias digitais constituem a materialidade da cultura digital, estas adentram as instituições de ensino passando a fazer parte da sua materialidade educativa, porque as instituições educacionais têm seu vínculo estrito com a cultura. Vale ainda ressaltar que a (re)configuração das práticas educativas por meio das plataformas digitais, tendem a demorar a acontecer.

Não queremos com isso dizer que não haja nas plataformas digitais, capacidade de desencadear mudanças significativas no processo de ensino-aprendizagem, bem como de minimizar a lacuna entre as práticas educacionais e as demais práticas sociais de docentes e discentes (MOREIRA; KRAMER, 2007). Podemos e devemos questionar o papel das novas tecnologias na educação, no entanto, devemos reconhecer que os recursos tecnológicos também favorecem a discussão da cultura. Se estamos pensando em uma educação de qualidade, dentre outros elementos, é preciso considerar a fusão de uma visão crítica dos processos de ensino e aprendizagem com o uso apropriado e criteriosos das novas tecnologias.

O elemento chave desse processo sem dúvidas é o professor. Notem que neste ponto as novas tecnologias exercem um efeito muito positivo, ou seja, as novas tecnologias educacionais desejam um docente disposto a correr riscos e a investir em sua atualização continuadamente. O que não quer dizer que a adesão das plataformas digitais e outros artefatos digitais 
tenham que suprimir formas antigas de diversidade cultural dentro das IES, estamos falando da necessidade de capacitação do profissional da educação para se mover da situação de viver restritamente seu cotidiano, para tornar-se ainda mais ativo na mudança de seu ambiente (MOREIRA; KRAMER, 2007).

Uma outra maneira de gerar ganhos com o uso das plataformas digitais nas IES é valorizar, acolher e criticar as vozes e as experiencias dos alunos. Pensamos que esta atitude é uma forma de recapturar o espírito cooperativo que as IES e os alunos tendem a perder na medida em que são adotados tais instrumentos digitais que os 'separam' fisicamente do convívio afetivo.

Coadunando com esta percepção, Rüdiger (2016, p. 30), acredita que as novas tecnologias podem promover uma mudança de consciência num sentido igualitário, cooperativo e emancipatório, se estes avanços forem devidamente apropriados e colocados a serviço do desenvolvimento de novas formas de sociabilidade dentro e fora da IES. Ou seja, o foco deve estar no engajamento e na construção de novas comunidades que possibilite processar mais e melhores informações e o compartilhamento do conhecimento de forma homogênea e colaborativa.

Por outro lado, conforme descrevemos no início deste tópico, a classe política, as elites empresariais e as forças do mercado exercem influência nesse contexto. As tecnologias educacionais e a forte pressão para sua adesão não são plenamente autônomas como gostaríamos que elas fossem, estão impregnadas de intencionalidades, muitas das vezes guiadas sob a batuta de uma ou mais das classes aqui mencionadas. Perante isso, Rüdiger (2016, p. 48) chega a afirmar que "[...] neste contexto, inerente a cibercultura, seja em que plano for, consiste essencialmente em um estágio mais avançado coletivamente de um processo de colonização da consciência pelo mercado que já opera no profissionalismo da mídia tradicional".

Segundo Oliveira, Guimarães e Lorenzetti (2016, p. 135) "Esta reflexão é vital para compreender o fenômeno tecnológico digital. Entender que os objetos não se materializam e adquirem valor espontaneamente é o primeiro passo para caminhar em busca de uma visão mais crítica da tecnologia". Desta forma, as atividades educacionais com o uso das tecnologias digitais não deveriam ser propostas de modo inflexível e descontextualizadas. As tecnologias educacionais digitais apresentam íntima relação com os interesses sociais e seu desenvolvimento se encontra dependente desses interesses. Pensando nisso, os autores destacam que:

Independentemente da vontade daqueles que utilizam as soluções tecnológicas, alguns artefatos são produzidos com fins específicos (nem sempre explícitos para os usuários) e carregam consigo interesses sociais, culturais, políticos ou religiosos embutidos em seu projeto [...] Assim, nem sempre os avanços tecnológicos são guiados pelos princípios da eficiência e da universalidade (não apresentam a mesma funcionalidade para todos) e eventualmente são desenhados com propósitos diferentes daqueles assumidos pelos seus usuários (OLIVEIRA; GUIMARÃES; LORENZETTI, 2016, p. 140).

Vale ressaltar que decidir utilizar as plataformas digitais de ensino não necessariamente determina e se configura como um modo de ensino e aprendizagem mais eficiente, mas como uma opção a mais de fazer educação, tal qual se propõe o ensino híbrido. Pode acontecer, por exemplo, de uma IES equipar-se com as ferramentas digitais mais inovadoras, de última geração, e continuar desenvolvendo por meio delas antigas tarefas. Enfim, a forma como se administra, as motivações pelas quais se adota, dentre outros fatores, podem, portanto, influenciar negativamente e contribuir para a não transformação positiva da cultura institucional, das normas, dos discursos, dos ritos e das práticas que marcam o fazer cotidiano das IES.

As plataformas digitais de ensino, as lousas interativas digitais, os tablets, os notebooks, os softwares, entre outros ligados a rede de comunicação mundial, assim como os objetos pessoais dos alunos (celulares e smartphones), hoje fazem parte da cultura educacional de modo geral, "[...] entretanto, a transformação da prática educativa para o uso destas tecnologias digitais deve ir além da simples aprendizagem técnica, ou ainda, ao desenvolvimento de habilidades e competências, para que 0 professor ensine e o aluno aprenda por meio dos dispositivos digitais" (MASCHIO, 2015, p. 590).

Foi pensando nisso que muitas empresas iniciaram uma corrida para propor em tempo hábil novas plataformas digitais para IES, enquanto outras tiveram que aperfeiçoar antigas e já experimentadas plataformas digitais, visando suavizar os impactos da transformação digital exigida pelos dias atuais. Tais plataformas tem a capacidade de facilitar a adequação frente às novas exigências do mercado, principalmente em países menos desenvolvidos e com pouco incentivo, como é o caso do Brasil. 
Algumas destas plataformas são bastante amplas na oferta de recursos, ao ponto de promoverem a digitalização agregando às rotinas de trabalho dos professores ferramentas mais inovadoras.

A organização sem fins lucrativos Khan Academy por exemplo, criou uma nova plataforma em que podemos encontrar recursos como: listas de conteúdos alinhados à BNCC, guia de início rápido para o aprendizado remoto, formação inicial para Educadores, sessões de desenvolvimento profissional, dicas de uso, trilhas que ensinam como engajar os alunos, etc. Ou seja, há toda uma estratégia para munir o professor visando o enfrentamento dos novos desafios contemporâneos que as IES enfrentarão.

Um outro exemplo de plataforma digital extremamente eficiente é o Moodle (utilizado em diversas universidades públicas e privadas), que vale ressaltar ser gratuito e está disponível na rede de Internet. Esta plataforma possui uma série funcionalidades que vão deste possibilidade do uso de metodologia ativa da sala invertida, onde o docente pode disponibilizar um vídeo ou texto previamente a aula, em que o aluno o assiste ou ler, no dia da aula seja presencial ou online debatem sobre o conteúdo estudado e posteriormente é passado uma atividade online dentro da plataforma para que 0 aluno consolide $o$ conhecimento adquirido neste processo. Tudo isso de uma maneira dinâmica e assertiva.

Enfim, poderíamos listar aqui uma série de outras plataformas digitais e suas mais variadas atividades disponíveis para o contexto do ensino híbrido nas IES. Mas gostariamos de chamar a atenção para alguns aspectos relevantes para uma ampla e melhor compreensão das implicações e proposições oriundos do uso das tecnologias educacionais, tais como, plataformas digitais, instrumentos e artefatos digitais etc.

De acordo com Dussel (2012 apud MASCHIO, 2015, p. 591),

[...] é preciso fazer uma revisão crítica do discurso e das produções que afirmam que os alunos, por serem nativos digitais, lidam com os dispositivos digitais com maior facilidade, interatividade e criatividade. Vários estudos, que contemplam o uso das tecnologias digitais por parte dos alunos em sala de aula, tem demostrado que as crianças e os jovens não são tão expansivos e "habilitados" para usar esses dispositivos na escola da mesma forma que utilizam livremente em outros espaços sociais.

Não há dúvidas que a inserção das tecnologias digitais na IES está possibilitando um momento de transição da cultura educacional. Lévy (1993; 1999) por exemplo entende as tecnologias educacionais digitais como tecnologia intelectual com capacidade de engendrar um novo modo de pensar o mundo, de entender a aprendizagem e as relações com esse mundo. Ou seja, ao lado da incorporação da tecnologia no âmbito do ensino e aprendizagem, cabe questionar o modelo de sociedade que se quer construir (MASCHIO, 2015).

Desse modo, visando aprofundar nossa concepção das tecnologias digitais propriamente ditas e seu uso no contexto das IES, compartilhamos a percepção de Oliveira, Guimarães e Lorenzetti (2016, p. 142) ao destacarem que "[...] o problema não reside na tecnologia como tal, mas na busca em criar instituições apropriadas ao exercício do controle humano sobre ela". 0 desafio que se impõe a cada um de nós e a todos nesse processo de democratização da atividade de ensino e aprendizagem por meio da mediação das tecnologias digitais é o de propiciar meios para o aumento da participação social nas decisões sobre sua produção e desenvolvimento.

Além do mais, do que adiantará termos presença em massa dos alunos em atividades mediadas pelas plataformas digitais, como é o caso nas IES privadas, sem engajamento por parte daqueles que deveriam ser protagonistas desse processo, mas não o são por falta de uma performance alinhada as exigências destas novas tecnologias.

As plataformas digitais são naturalmente potencializadoras da baixa interatividade, o que não quer dizer que isso seja uma regra incapaz de ser modificada, essencialmente estamos falando de um artefato, sem afetividade, que funciona por meio de comandos, logo, extrair as suas potencialidades positivas é uma condição sine qua non para quem a opera no sentido de que haja materialidade do processo de ensino e aprendizagem mediado por estas novas tecnologias educacionais.

Por fim, o convido a refletir em um dos papeis fundamentais exercido pelas IES na sociedade moderna, isto é, formar capital humano sob demanda social. Ora, se um dos papéis das IES é considerado de caráter nobre conforme acabo de citar, por que a escolha das tecnologias educacionais digitais e a decisão de inseri-la no processo de ensino e aprendizagem deveriam 
estar abaixo deste nível de exigência? Deveríamos levar em consideração que as novas tecnologias podem produzir abundância para todos, eliminar as necessidades de excessiva quantidade de trabalhos pesados e alienantes, e aumentar 0 'reino da liberdade' dos homens (MARCUSE, 2001).

Ou seja, pensar em inserir as plataformas digitais no contexto das IES é pensar para além de um trabalho controlado pela tela de um computador, tablet ou smartphone, em que as pessoas não precisam mais interagir e conhecem cada vez menos a natureza do resultado da sua produção. As tecnologias digitais podem ser um instrumento a serviço ou contra o projeto de emancipação do sujeito.

\title{
40 uso das plataformas digitais durante o afastamento social sob o olhar dos professores das IES
}

A Internet, as diversas plataformas digitais e as mídias sociais ganham evidência ainda maior no contexto atual, diante do afastamento social causado pela pandemia do Coronavírus, no que diz respeito ao uso de tais ferramentas para as práticas institucionais diante do processo de ensino e aprendizagem.

O fechamento das instituições de ensino em virtude da propagação do Coronavírus (Covid-19) alterou a rotina dos estudantes de todos os níveis, desde a educação básica ao ensino superior, se estendendo a níveis de pós-graduação, que passaram a permanecer na sua residência, sem poder ter acesso ao ensino presencial ofertado pelas instituições.

Por conta da suspensão das aulas presenciais, as instituições de ensino precisaram reorganizar as práticas desenvolvidas, a fim de minimizar os danos ao processo escolar e acadêmico. Diante deste contexto, a partir da decisão tomada por governos e pela iniciativa privada como parte dos protocolos de emergência gerados pela pandemia do novo Coronavirus (Covid-19), o uso de ferramentas tecnológicas passou a virar estratégia de condução das instituições a fim de permitir aos estudantes continuar aprendendo mesmo que em casa, através do direcionamento e acompanhamento por parte do professor via online, potencializando o ensino remoto.

Ao nos referirmos sobre o ensino remoto nesta nova condução das práticas educacionais, é importante destacar que este não se configura enquanto modalidade de Educação a Distância (EaD), mas sim, como solução temporária com o uso de recursos digitais, como as plataformas, para manter a relação professor e aluno impedida pelo afastamento social. De acordo com o Instituto Nacional de Estudos e Pesquisas Educacionais Anísio Teixeira (INEP), à educação a distância é

\begin{abstract}
caracterizada como modalidade educacional na qual a mediação didático-pedagógica, nos processos de ensino e aprendizagem, ocorre com a utilização de meios e tecnologias de informação e comunicação, com pessoal qualificado, políticas de acesso, acompanhamento e avaliação compatíveis, entre outros, de modo que se propicie, ainda, maior articulação e efetiva interação e complementariedade entre a presencialidade e a virtualidade "real", o local e o global, a subjetividade e a participação democrática nos processos de ensino e aprendizagem em rede, envolvendo estudantes e profissionais da educação (professores, tutores e gestores), que desenvolvem atividades educativas em lugares e/ou tempos diversos (INSTITUTO NACIONAL DE ESTUDOS E PESQUISAS EDUCACIONAIS ANÍSIO TEIXEIRA, [20--], não paginado).
\end{abstract}

Diferenciando-se do ensino remoto, principalmente pelas características que este último apresenta, como: aula ao vivo ou gravada, nos dias e horários da presencial; interação com o seu professor da disciplina; materiais personalizados e elaborados pelo professor da disciplina; calendário próprio, de acordo com plano de ensino, adaptado para a situação emergencial; e, avaliações e testes personalizados, criados pelo professor da disciplina, conforme conteúdo abordado nas aulas remotas. Entretanto, este ensino pode dar força para as instituições, principalmente, de ensino privado, na proposta de ensino híbrido ou até mesmo, na oferta de cursos na modalidade EaD.

Para Ristoff (2007), apesar de inúmeras experiências bem-sucedidas em outros países, a modalidade de EaD continua sob fogo cruzado no Brasil, com o argumento de que vai piorar a qualidade. Alguns até reconhecem seu efeito democratizante, mas temem que traga ainda mais dificuldades a um sistema educacional com problemas. Por isso, é necessário ter cuidado e criticidade com a propagação da oferta de $\mathrm{EaD}$, que não apresenta o possível potencial da modalidade, ao contrário, 
corrobora com a desvalorização e precarização docente, causada pelos interesses meramente econômicos das empresas que produzem ou gerenciam a proposta de tal modalidade.

No atual contexto pandêmico, o ensino remoto, enquanto uma proposta de integração do estudante ao processo de ensino e aprendizagem, aponta para a necessidade dos professores repensarem suas práticas, atribuindo as mesmas, inovação, interatividade e dinamismo. Afirma Masetto (2003, p. 45): "A sala de aula, seja ela presencial ou virtual, deve ser transformada em um ambiente de interação, no qual os saberes inicialmente apresentados por professor e alunos são enriquecidos pelos saberes construídos nessa interação, ou seja, a aula funciona numa dupla direção".

Contudo, é importante perceber que os ambientes de aprendizagem possibilitados pelo uso das tecnologias digitais por si só, não produzem a aula interativa, muitos são os complicadores que dormitam neste tipo de experiência de modo a dificultar o processo, tais como: formação adequada dos professores para o domínio de tal ferramenta; boa conectividade; ausência de recursos adequados por parte dos estudantes e professores também; acesso á internet; dentre outros. Então, quando perguntado sobre quais os desafios e complicações para o acontecimento das aulas nas plataformas digitais, os professores, de uma forma geral, apresentaram falas relacionadas com os aspectos acima:

Dificuldade de conectividade e ausência de equipamentos necessários para o acompanhamento das aulas. Tradicionalmente não temos cultura digital (Narrativa do professor A).

A qualidade da conectividade (para alunos e docente); a falta de hábito do grupo e professora nessa modalidade (Narrativa do professor B).

Internet, computador e celular com qualidade. Conseguir a participação e acompanhamento dos estudantes. (Narrativa do professor C).

Ter altos recursos tecnológicos não garante a aprendizagem, porém, ter uma boa infraestrutura e conectividade é importante para proporcionar a interação e participação entre docente e estudantes, sem interrupções, a fim de garantir uma aula harmoniosa e fluída, que busque a dialogicidade sempre. No entanto, para além destes fatores, é preciso debater que a tecnologia não é o fim para a aprendizagem, mas sim uma propulsora ao processo e que seu uso deve vir acompanhado de reflexão e avaliação por parte do professor, como também, de atividades significativas. As modificações geradas pelo uso da tecnologia, no ramo educacional, contribuem para substanciais mudanças na forma de ensinar, ao mesmo tempo em que, possibilita aos alunos validarem o conteúdo ministrado em sala de aula (SILVA; BARBOSA, 2018). Percebe-se esta análise diante das narrativas apresentadas pelos professores abaixo:

Inicialmente a dificuldade foi relacionada ao domínio da ferramenta, depois, a nova configuração das aulas exigiu um replanejamento de toda ação pedagógica prevista para sala de aula presencial (Narrativa do professor F).

Se houver plano de trabalho com procedimentos claros, bem explicitados, os desafios são minimizados (Narrativa do professor J).

Considera-se então, que a falta de formação adequada do professor para o uso de tais plataformas e redirecionamento das suas práticas diante dessas possibilidades, interfere diretamente na atuação do professor no ensino remoto, principalmente por considerar que o "[...] ensino remoto não deve se resumir a aulas online, diversificar as experiências de aprendizagem continua sendo relevante e necessário" (MINISTÉRIO DA EDUCAÇÃO, 2020, p. 11).

Corrobora a autora Jordão (2009, p.12), ao afirmar que,

[...] a formação do professor deve ocorrer de forma permanente e para a vida toda. Sempre surgirão novos recursos, novas tecnologias e novas estratégias de ensino e aprendizagem. O professor precisa ser um pesquisador permanente, que busca novas formas de ensinar e apoiar alunos em seu processo de aprendizagem.

Entende-se, dessa forma, que não basta apenas ter acesso às novas ferramentas tecnológicas, mas é preciso ter a consciência de que uma aula enquadrada no uso de novas tecnologias exige outro desafio a ser enfrentado pelo professor, 
que é preparar esse ambiente e ter condições de lidar com as ferramentas que se irá utilizar e buscar identificar a familiaridade que o estudante tem com determinada ferramenta. No que diz respeito a essa familiaridade do estudante, os professores apresentaram as seguintes narrativas:

A participação tem ocorrido de forma interativa e dinâmica, no entanto, algumas alunas e alunos têm tidos algumas dificuldades devido à falta de domínio e familiaridade com o uso dos aparatos tecnológicos digitais conectados a internet, com recuso didático pedagógico. A grande maioria, anteriormente usava tais aparatos apenas para acessar as redes sociais (Professor $A$ ).

Nas primeiras semanas de atividades remotas houve muito mais participação e interação. Atualmente, percebo um pouco mais de cansaço e distanciamento (Professor $\mathrm{J}$ ).

A frequência não passa de $60 \%$ da turma e o envolvimento é quase sempre dos mesmos grupos (Professor G).

Em algumas turmas a participação é maior do que em outras. Mas, considero a frequência baixa em comparação com a quantidade de pessoas que tem na turma (Professor $\mathrm{H}$ ).

Tais narrativas apresentam que a não familiaridade com as ferramentas contribuem para a baixa participação e interação dos estudantes nas aulas online, ao mesmo tempo em que, traz pontos que precisam ser debatidos enquanto prejuízos para a aprendizagem dos estudantes, a ausência das aulas, entendendo que mesmo com os complicadores dessa nova dinâmica de ensino, é importante a presença do estudante nas aulas para o acompanhamento dos conteúdos diante do período de afastamento social causado pela Covid-19. Entretanto, as questões socioeconômicas interferem diretamente no acesso dos estudantes nas aulas, e, em relação ao curso de Pedagogia especificamente, por ser um curso majoritariamente de pessoas de baixa renda, que buscam no ensino superior uma oportunidade de ascensão social, tais questões potencializam o distanciamento dos estudantes no ensino remoto. Afirma Neves, Santos e Gomes (2012, p. 25) que, isso se dá, principalmente porque "[...] as relações entre informação, Estado, economia e sociedade se dão de maneira desigual, promovendo mudanças na maneira dos indivíduos desenvolverem as condições de ligação com essas esferas". Percebemos que os professores apresentaram uma sensibilidade e criticidade diante do exposto:

Além da dificuldade de acesso, pois não conseguem dar conta de todas as leituras e atividades com os dados móveis, as estudantes enfrentam vários problemas, como desemprego, preocupação na manutenção da casa, dentre outros (Narrativa do professor E).

O problema maior ter sido as dificuldades dos estudantes em acessar e participar das aulas e realizar as atividades. $\mathrm{O}$ fato da maioria, compor estudantes de baixar renda e não ter um pacote de internet que permita acesso ilimitado dificulta no desenvolvimento das atividades remotas (Narrativa do professor A).

No entanto, em alguns contextos como o nosso, por exemplo, a limitação de recursos (financeiros e materiais), impede a participação de um número considerável de estudantes (Narrativa do professor I).

Entender que as tecnologias e o uso das plataformas digitais são estratégias positivas para este período de afastamento social é necessário, tão quanto perceber que apesar deste movimento perpassar por formas de manutenção e de transformação das relações, podem acentuar as barreiras entre os que podem e os que não podem ter acesso às tecnologias digitais, incluindo e excluindo pessoas (LÉVY, 1996). Dessa forma, as práticas educacionais devem ser flexibilizadas e as estratégias serem as mais diversas possíveis a fim de buscar minimizar os impactos no processo de ensino e aprendizagem causados por este momento. Da mesma forma, apresenta-se necessário a ampliação de outros canais de comunicação entre professor e estudantes para além das aulas online. Diante disto, foi perguntado aos professores, sobre desafios enfrentados no acompanhamento das atividades domiciliares no período de afastamento social, e os mesmos relataram da seguinte forma:

Considero que a presença limitada dos estudantes no espaço virtual, tem demandado uma atenção extremamente maior por parte dos ausentes nas aulas. Muitas mensagens por email, whatsapp... A sensação é de que preciso dar a mesma aula dezenas de vezes, ocasionando desgaste físico, emocional e mental (Narrativa do professor I). 
Não ter um ambiente adequado para realizar as aulas online; responder aos grupos do whatsApp e individual; atender demandas específicas de alunos que não consegue realizar a atividade no AVAR; orientar estudantes que estão frustrados por não conseguir acompanhar a dinâmica das atividades remotas, entre tantas outras (Narrativa do professor A).

Aumento considerável da quantidade de trabalho, somado à isso, desgaste proveniente da insegurança em relação ao recebimento da remuneração salarial. Esses fatores têm comprometido o bem-estar, gerando ansiedade, insônia, desconforto gástrico e enxaqueca (Narrativa do professor D).

Como grande parte não tem acesso à internet banda larga, o retorno das atividades é muito lento. As estudantes têm dificuldade em entender que a professora não está à disposição todos os dias e em todos os horários... Além disso, e acho o mais importante, percebo que as atividades domiciliares apresentam lacunas que só as aulas presenciais conseguem resolver (Narrativa do professor $\mathrm{J}$ ).

A partir desta última narrativa, faz-nos pensar sobre a comparação falaz entre o ensino marcadamente presencial e o ensino a distância. A comparação entre ambas, embora tantas vezes combatida, continua inevitável. González (2007) explica que as comparações podem ser odiosas, porém, são inevitáveis, ainda mais quando queremos saber qual a imagem que a sociedade tem desta proposta educativa. De acordo com o autor, "[...] somente se pode ensinar tendo frente a frente os alunos" (GONZÁLEZ, 2007, p. 87, tradução nossa).

É válido considerar que o momento atual, de afastamento social, corrobora para uma prática educacional que tenha as plataformas digitais como égide do processo de ensino e aprendizagem, entretanto, como foi apresentado, existem complicadores que entornam essa proposta pedagógica e precisam ser debatidos, inclusive para avançar na discussão de um ensino com metodologias ativas e modelos híbridos, o que requer não somente o uso dos recursos digitais, mas formação adequada, relação dialógica e política das ações realizadas neste ensino.

\section{Considerações Finais}

Diante do contexto atual, situação inusitada e extraordinária em que vivemos de afastamento social, resultado de uma pandemia que impactou a forma da sociedade se organizar e se relacionar entre pares, não há como desconsiderar que os desafios são muitos, as indagações são diárias e os estranhamentos, necessários. A nova forma de interação, principalmente, nos espaços educacionais foi ganhando força neste período, o ensino remoto, como tentativa de comunicação, diálogo e relação entre professor e estudante, ensino e aprendizagem, mesmo que ofertado a distância. Para a sociedade, de forma geral, as tecnologias modificam e se modificam em si mesmas pela ação transformadora do homem, por meio delas próprias e, no contexto mais atual, representam o suporte para uma revolução digital e, consequentemente para novas modificações nas relações humanas (NEVES, 2010).

É importante destacar, inicialmente, que essa relação não vem no singular, nem de forma isolada, ela se estabelece com a troca, com o encontro mesmo que através de uma tela, com o mínimo de contato possível para o direcionamento de conteúdos e atividades acadêmicas. E, nesta relação, o professor e o estudante devem ser coadjuvantes no ensino remoto, pela necessidade que se impõe por aulas dinâmicas e interativas a partir do uso das plataformas digitais. Por isso, o professor se tornou sujeito colaborador do nosso estudo, enquanto sujeito de fala a partir do seu lugar de atuação, no intuito de colocar suas impressões diante deste momento atual, pensando a sua prática, as estratégias lançadas e os desafios encarados pela adesão do ensino remoto.

Percebemos, a partir das narrativas apresentadas, que os desafios entornam diante dos pontos de boa conectividade; ausência de recursos adequados; acesso á internet; ausência dos estudantes nas aulas remotas, como também, a participação e interação dos mesmos quando presentes; disponibilização de uma carga horária para além das aulas remotas por outros canais de comunicação; e, formação adequada dos professores para o domínio das ferramentas. Sabe-se que, muito dos pontos apresentados, principalmente, pela especificidade apresentada ao público do curso de graduação escolhido, de Pedagogia, ou seja, considerados de baixa renda e com poucos recursos financeiros, é resultado das questões socioeconômicas destes estudantes, que dificulta o acompanhamento ao ensino remoto. 
Embora, as questões socioeconômicas precisem ser consideradas como fortes complicadores diante das impossibilidades no acompanhamento das aulas online, existem fatores que estão ligados diretamente a falta de formação dos professores na atuação do ensino remoto, principalmente por que, tal proposta adotada pelas instituições, se configura enquanto uma solução temporária e foi direcionada como remediação ao afastamento social e não, é vista como uma estratégia adotada nas práticas educacionais. Ou seja, o professor não está preparado para este ensino, precisando como consequência disto, se adaptar as ferramentas de forma desorientada, acelerada e sobrecarregada de informações a fim de dar conta das demandas apresentadas.

Por fim, é importante destacar que estamos em um momento de muitas incertezas, inquietações, angústias, medos e anseios causados pelo afastamento social por proteção ao Coronavírus, ao mesmo tempo em que, momentos de descoberta, renovação e ressignificação, o que implica diretamente nas práticas educacionais desenvolvidas não somente durante o ensino remoto, mas, principalmente, no repensar das práticas já realizadas em sala de aula e nas possibilidades ou impossibilidades que este ensino pode agregar a tais práticas, redirecionando o trabalho desenvolvido.

\section{Referências}

FEENBERG, Andrew. Questioning technology. 3. ed. London; New York: Routledge, 2001.

FEENBERG, Andrew. Transforming technology: a critical theory revisited. Oxford: Oxford University Press, 2002.

GONZÁLEZ, Jaime Ricardo. Imagem social de la educación a distância. In: MENA, Marta (Org). Construyendo la nueva agenda de la educación a distancia. Buenos Aires: IA Curjia, 2007, p. 251-279.

INSTITUTO NACIONAL DE ESTUDOS E PESQUISAS EDUCACIONAIS ANÍSIO TEIXEIRA. Educação a Distância. Brasília, [20--]. Disponível em: http://inep.gov.br/ead. Acesso em: 23 jun. 2020.

JORDÃO, Teresa Cristina. Formação de educadores: a formação do professor para a educação em um mundo digital. Boletim Salto para o Futuro: Tecnologias digitais na educação, v. 19, n. 19, p. 9-17, nov./dez. 2009. Disponível em: http://portaldoprofessor.mec.gov.br/storage/materiais/0000012178.pdf Acesso em: 1 jul. 2020.

LÉVY, Pierre. As tecnologias da inteligência: o futuro do pensamento na era da informática. Rio de Janeiro: Editora $34,1993$.

LÉVY, Pierre. O que é virtual? Rio de Janeiro: Editora 34, 1996.

LÉVY, Pierre. Cibercultura. São Paulo: Loyola, 1999.

MARCUSE, Herbert. Guerra, tecnologia y fascismo: textos inéditos. Medellí, Colombia: Editora Universidad de Antioquia, 2001.

MASCHIO, Elaine Cátia Falcade. A cultura digital na escola: reflexões sobre a transformação da prática educativa escolar. Revista Intersaberes. Curitiba, v. 10, n. 21, p. 577-594, set./dez. 2015. Disponível em:

https://www.uninter.com/intersaberes/index.php/revista/article/view/897. Acesso em: 1 jul. 2020.

MASETTO, Marcos Tarciso. Competência pedagógica do professor universitário. São Paulo: Summus, 2003.

MINISTÉRIO DA EDUCAÇÃO. Nota técnica ensino a distância na educação básica frente à pandemia da Covid-19. Brasilia: MEC, 2020. Disponível em: http://docplaver.com.br/184349027-Ensino-a-distancia-na-a-educacao-basica-frente-a-pandemia-da-covid-19.html. Acesso em: 1 jul. 2020.

MOREIRA, Antônio Flávio Barbosa; KRAMER, Sônia. Contemporaneidade, educação e tecnologia. Educação \& Sociedade, Campinas, v. 28, n. 100, p. 1037-1057, out. 2007. Disponível em: https://www.scielo.br/pdf/es/v28n100/a1928100.pdf. Acesso em: 1 jul. 2020.

NEVES, Bárbara Coelho; SANTOS, Raquel Rosário dos; GOMES, Henriette Ferreira. A condição estruturante das tecnologias nas relações sociais: potencialidades na interlocução entre biblioteca e usuário. Informação \& Sociedade: Estudos, João Pessoa, v. 22, n. 3, p. 25-31, set./dez. 2012. Disponível em: https://periodicos.ufpb.br/ojs2/index.php/ies/article/view/10106/8574. Acesso em: 1 jul. 2020.

NEVES, Bárbara Coelho. Pontos de inclusão digital baianos: uma abordagem cognitiva baseada na convergência de recursos e na mediação. 2010. 210 f. Dissertação (Mestrado em Ciência da Informação) - Universidade Federal da Bahia, Salvador, 2010. Disponível em: https://repositorio.ufba.br/r//bitstream/ri/7918/1/Disserta\%c3\%a7\%c3\%a30\%20-\%20Barbara\%20Coelho\%20Neves.pdf. Acesso em: 2 jul. 2020.

OLIVEIRA, Silvaney de; GUIMARÃES, Orliney Maciel; LORENZETTI, Leonir. O enfoque CTS e as concepções de tecnologia de alunos do ensino médio. Alexandria: Revista de Educação em Ciência e Tecnologia, Florianópolis, v. 9, n. 2, p. 121-147, nov. 2016. Disponível em: https://periodicos.ufsc.br/index.php/alexandria/article/view/1982-5153.2016v9n2p121/32839. Acesso em: 1 jul. 2020.

PUCCI, Bruno. Theodor Adorno e a frieza burguesa em tempos de tecnologias digitais. Cadernos IHU ideias, São Leopoldo, v. 10, n. 172, p. 3-16, 2012. Disponível em: http://www.ihu.unisinos.br/images/stories/cadernos/ideias/172cadernosihuideias.pdf. Acesso em: 1 jul. 2020.

RISTOFF, Dilvo. Aluno a distância vai melhor no Enade. Folha de São Paulo, São Paulo, 10 set. 2007. Disponível em: http://goo.gl/5TEmgA. Acesso em: 1 jul. 2020.

RÜDIGER, Francisco. As teorias da cibercultura: as perspectivas, questões e autores. 2. ed. Porto Alegre: Sulina, 2016. 
SILVA, Cristiano Moreira da; BARBOSA, Ricardo Rodrigues. Uso das novas tecnologias na validação dos conteúdos ministrados durante as aulas. Informação \& Sociedade: Estudos, v. 28, n. 2, p. 133-148, maio/ago. 2018. Disponível em:

https://periodicos.ufpb.br/ojs2/index.php/ies/article/view/38668/20798. Acesso em: 23 jun. 2020.

SOUSA, Robson Pequeno de; MOITA, Filomena da M. C. da S. C.; CARVALHO, Ana Beatriz Gomes (Org.). Tecnologias digitais na educação. Campina Grande: EDUEPB, 2011. Disponível em:

http://www.clam.org.br/bibliotecadigital/uploads/publicacoes/1484 991 sousa-9788578791247.pdf. Acesso em: 1 jul. 2020.

TODOS PELA EDUCAÇÂO. Nota Técnica: Ensino a distância Educação Básica frente à pandemia da Covid-19. São Paulo: Todos pela Educação, 2020. Disponível em: https://www.todospelaeducacao.org.br/ uploads/ posts/425.pdf. Acesso em: 23 jun. 2020.

Artigo submetido em: 24/06/2020.

Aceito em: 02/07/2020.

\section{UFCA UNIVERSIDADE}

Centro de Ciências Sociais Aplicadas

Mestrado Profissional em Biblioteconomia

Este periódico é uma publicação do Programa de Pós-Graduação em Biblioteconomia da Universidade Federal do Cariri em formato digital e periodicidade quadrimestral. 